\title{
Cloning and characterization of the cDNA encoding human adenylosuccinate synthetase
}

\author{
Steven M. Powella, Howard Zalkin ${ }^{a}$ and Jack E. Dixon ${ }^{b}$ \\ "Deparment of Biochemistry, Purdue University, West Lafayette, IN 49707, USA and 'Department of Biologicul Chemistry, \\ The University of Michigan, Ann Arbor, MI 48109, USA.
}

Received 21 February 1992; revised version received 30 March 1992

\begin{abstract}
Adenylosuccinate synthetase (AS) calalyzes the first committed step in the conversion of IMP to AMP. A cDNA wus isolated from a human liver library which encodes a protein of 455 amino acids $\left(M_{\mathrm{r}}\right.$ of 49.925). Alignments of human, mouse, Dictyostelium disioideum and $E$. coli AS sequences identily a number of invariant residues which are likely to be important for struciure and/or catalysis. The human AS sequence was also $19 \%$ ideritical to the human urea cycle enzyme, arginosuccinate synthetase (ASS), which catalyzes a chemically similar reaction, Both human liver and HeLa AS mRNA showed signals of 2.3 and $2.8 \mathrm{~kb}$. An unmodified $\mathrm{N}$-terminus is required for function of the human AS enzyme in $E$. coli mutants lacking the bacterial enzyme. The human cDNA provides a means to assess the possible role of AS abnormalities in unclassified, idiopathic cases of gout.
\end{abstract}

Recombinant DNA; De novo purine nucleotide synthesis; Gout

\section{INTRODUCTION}

The genes for de novo purine nucleotide (nt) synthesis in bacteria have been analyzed in detail ([28] references therein). Only recently have molecular approaches been applied to characterize these genes in higher eukaryotes. Avian cDNAs encoding enzymes which catalyze eight of the ten steps leading to IMP have been isolated in our laboratory by functional complementation of $E$. coli pur mutants $[1,2,6,18]$. Similar attempts to complement an $E$. coli pur $A$ mutant were unsuccessful in isolating the eukaryotic CDNA for AS.

AS catalyzes the reaction shown in Fig. 1, which is the first committed step in the pathway leading from IMP to AMP, and is subject to feedback inhibition by AMP [21]. AS activity is present in most tissues but is highest in skeletal muscle, heart, and testes $[5,15,17,21]$. Ele-

Abbreviations: Ade.H, adenylosuccinate lyase gene; AMP, adenosine monophosphate; AS, adenylosuccinate synthetase; ASS, arginosuccinale synthetase; ATP, adenosine triphosphate; bp, base pair; CAMP, cyclic adenosine monophosphate; $\mathrm{GGMP}$, cyclic guanosine mono. phosphate; $\mathrm{CHO}$, Chinese Hamster Ovary; GDP, guanosine di. phosphate; GTP, gugnosine monophosphate; IMP, inosine monophosphate; kb, kilobase(s); kDa, kilodalton(s); nt, nucleotide; PCR, polymerase chain reaction; $\mathrm{P}_{\mathrm{j}}$ inorganic phosphate; $\mathrm{PP}_{\mathrm{i}}$, pyro. phosphate; Pipes, piperazine- $N, N^{\prime}$-bis[2-ethane-sulionic acid]); pur $A$, $E$ coli gene encoding adenylosuccinate synthetase; SDS, sodium do. decyl sulfate; SSC, sodium chloride, sodium citrate; SSPE, sodium chloride, sodium phospinate containing EDTA.

Correspondence address: J.E. Dixon, Deparment of Biological Chemistry, The University of Michigan Medical School, Room $5416 \mathrm{Medi}$. cal Science I Building, Box 0606, Ann Arbor, MI 48109-0506, USA Fax: (1) (313) $76.34-4581$ vated activity has been noted in tumors [10]. Two isozymes have been reported in tissues of rat, rabbit, and chicken [21]. A basic form, having a pI of 8.9 and low $K_{\mathrm{m}}$ for aspartate, has been assigned a role in an $\mathrm{nt}$ interconversion cycle and may function in purine salvage $[20,21]$. An acidic form, with a pI of 5.9 and a low $K_{\mathrm{m}}$ for IMP, is thought to have a biosynthetic role. However, only a single AS locus has been identified in $\mathrm{CHO}$ cells [22]. Somatic cell hybridization studies have localized the human AS gene to the long arm of chromosome 1, between the centromere and 1q12 [14]. Prior to the start of this work, the only AS sequence available was that from the cloned $E$. coll gene [27]. Our efforts to obtain the human CDNA were greatly aided by the availability of a mouse cDNA sequence [9]. During the course of our work, the sequence of AS from Dictyostelium discoideum was published [26].

This paper reports the isolation and analysis of the human cDNA encoding AS. This human CDNA will allow examination of the relationship of AS to human disease states. The human sequence is of interest clinically. In addition, the human enzyme has a predicted isoelectric point of $\sim 7$, as opposed to the suggested $\mathrm{pI}$ of 5 and 9 for the two rat isoforms. No information is available regarding the human isoforms and few mutations in AS are known in humans suggesting that the enzyme is important for growth and development. A mutated murine lymphoma cell line has been identified with a partial defiency in AS $[23,24]$. These cells synthesized large amounts of $\mathbf{i}(\bar{P} \mathcal{P}$ which is secreted as inosine, thus suggesting a link between the AS deficiency and hyperuricemic states. A defective AS may contribute to 
<smiles>[R6]n1cnc2c(=O)[nH]cnc21</smiles>

IMP<smiles>N[C@@H](CC(=O)[O-])[C@@H]([NH3+])[OH2+]</smiles>

Aspartate<smiles>[R16]n1cnc2c(NC(CC(=O)O)C(=O)O)ncnc21</smiles>

Adenylosuccinate<smiles>NC(=O)NCCCC(N)C(=O)OCc1ccccc1</smiles>

Cirrulline

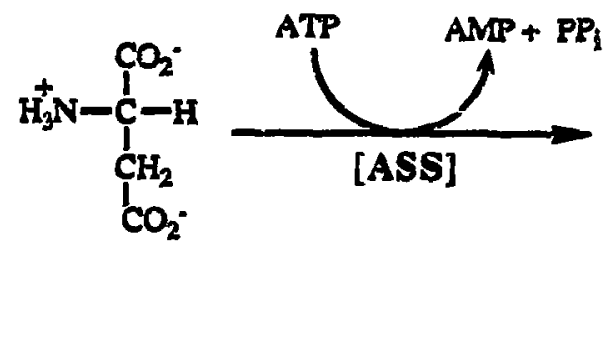

Aspartate<smiles>[NH3+]C(CC(C(=O)O)C(=O)O)NCCCC([NH3+])C(=O)O</smiles>

Argininosuccinate

Fig. 1, Reactions catalyzed by AS and ASS.

unclassified idiopathic gout. Isolation of the human cDNA is the first necessary step in further exploring metabolic defects in AS.

\section{EXPERIMENTAL}

The template for first strand cDNA synthesis was human lymphoblast RNA. First strand synthesis was carried out using AMV reverse transcriptase as outlined by the manufucturer's specifications (Invitrogen). The resultant CDNA was used as template for PCR as suggested by the manufacturer's specifications (Perkin Elmer Cetus: Gene Amp kit). Degenerate oligonucleotide primers were designed based upon conserved amino acid sequences common to the $E$. coli [27] and mouse AS [D]. Two, $26 \mathrm{nt}$ primers were synthesized with EcoRI and HindIII linkers: 5'-end primer, CATGAATTCCA(A/G)TGGGNNGA(T/ C) GA(AVG)GG; 3'-end primer, ATGAAGCTTACNACNCC(G/ A)TTNCC(A/G/T)AT. The first two thermo-cycles were as follows: $94^{\circ} \mathrm{C}, 1 \mathrm{~min} ; 37^{\circ} \mathrm{C}, 2 \mathrm{~min} ; 72^{\circ} \mathrm{C}$ over $2 \mathrm{~min} ; 72^{\circ} \mathrm{C}, 2 \mathrm{~min}$. The subsequent 40 thermo-cycles were $94^{\circ} \mathrm{C}, 1 \mathrm{~min} ; 50^{\circ} \mathrm{C}, 2 \mathrm{~min} ; 2^{\circ} \mathrm{C}, 2 \mathrm{~min}$ followed by an extension at $72^{\circ} \mathrm{C}$ for $20 \mathrm{~min}$. The amplified, $200 \mathrm{nt}$ fragment was then subcloned into $\mathrm{M} 13 \mathrm{mp} 18$ for sequence analysis.

A $\lambda$ gt1 1 human liver cDNA libraly [13] was probed with the labeled PCR product described above. Approximately 200,000 plaques were plated and duplicate lifts were made onto nitrocellulose filters. Hybridization, washing of the filters and autoradiograpny was carried out as previously described [2]. Following plaque purification, the insert from the DNA was subcloned for sequencing.

RNA was extracted from HeLa cells and human liver as described
[7]. Human liver poly(A) ${ }^{+}$RNA was selected by oligo d(T)-eellulose chromatograpiny [4]. RNA was fractionated by clectrophoresis in a $1.0 \%$ agarose gel containing formaldehyde and transferred to a nitro. cellulose filter as described [16]. Hybridization with the $2.0 \mathrm{~kb}$ cDNA insert was conducted at $42^{\circ} \mathrm{C}$ for $18 \mathrm{~h}$ as previously described [2]. Filters were washed at room temperature is $0.1 \%$ SDS/ $0.25 \times S S P E$ for $30 \mathrm{~min}$ followed by autoradiography. Subsequent washes and autoradiograplss were conducted at $37^{\circ} \mathrm{C}, 42^{\circ} \mathrm{C}$, and $65^{\circ} \mathrm{C}$. Functional complementation was carried out as follows. An N'col (nt 73) to BamHI restriction fragment containing an AS coding sequence (Fig. 2) was subeloned into the expression vector pTRC-97c [3]. The resulting plasmid was transformed into two $E$. coli purA strains: PCO950 (purA54, argi6l, argF58, serB28, thr25, tonA49), and ES4 (purA45, lacYl or Z4, tonA2, tsx-1 or tsx-70, supE44, sai-6, mil2). The cells were grown in minimal medium [6] supplemented with $0.1 \%$ avid hydrolyzed casein, $0.2 \mu \mathrm{g} / \mathrm{ml}$ thiamine and ampicillin $(50 \mu \mathrm{g} / \mathrm{ml})$.

\section{RESULTS AND DISCUSSION}

\subsection{Isolation and sequence of the human cDNA encoding AS}

A human PCR product of approximately 200 bp was amplified using degenerate oligonucleotide primers based on conserved regions in $E$. coli and mouse AS amino acid sequences [9]. Sequence analysis deminonstrated that the PCR product was similar but not identical to both $E$. coli and mouse AS. The PCR product 
73 ATGCCGTTCGCGAGACCTACCCGGCGGCATCCTCCCTGCCCAACGGCGATTOCGGCCGCCCGAGGGCCGGCCGGAGGA

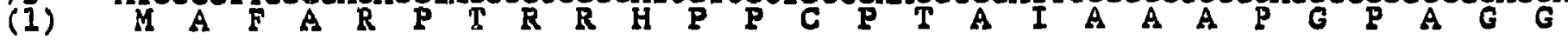

151. AACCGGGTGACGGTGGTGCTCGTGCGCAGIGGGGCGACGAGGCAAAGGGAAGGTGGTGGACCTGCTGEOGCAGGAC

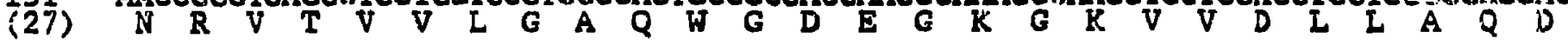

229 GCCGACATCETGTGCCGCLGCCAGGGAGGAAGTAGTGCTGGCCATACAGTTGTTGTGGATTCTGTGGAATATGATTTT

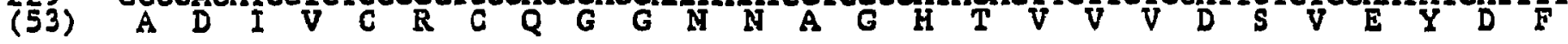

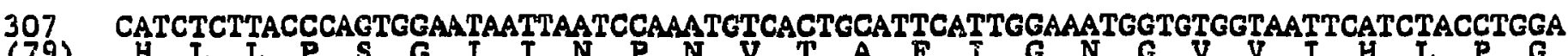

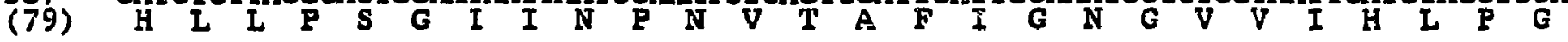

385 TTGTTTGAAGAGCAGGGAAAATGTCAAAAAGGAAAGGACTAGAAGGCTGGGAAAAAGGCTTATTATATCTGAC

(105) L F E E A E K N V Q K G K G L E G W E K R L I I S D

463 AGAGCTCATATTETATTTGATTTTCATCAACCACCTGATGGTATCCAGGAACAACAGAGACAAGAACAAGCAGGAAAA

(131) $R$ A H I V F D F H Q A A $D$ G I Q E Q Q R Q E $Q$ A $G$ K

541 AATTTGGGTACAACAAGAAGGGCATTGCCCCACTTTATTCTCCAAAGCTGCTCGGAGTGGACTCAGGATGTGCGAC

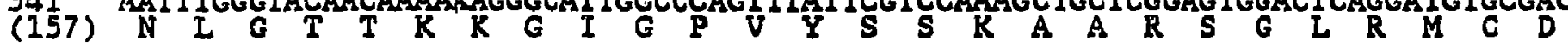

519 CTTGTTTCTGACTTTGATGGCTTCTCTGAGAGGTTTAAAGTCTAGCTAACCAATACAAATCTATATACCCCACTTTG

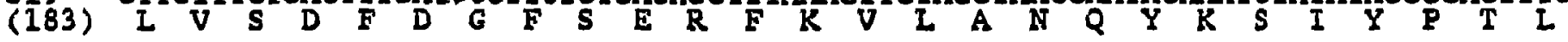

697 GAAATAGACATTGAAGGTGATTACAAAAACTCAAGGGTTATATGGAAAAGATTAAACCAATGGTGAGAGATGGAGTT (209) E I D I. E G E L Q K L K G Y M E K I K $P$ K V R D G V

775 TATTTTCTATATGAGGCCCTACATGGACCACCAAGGAAATCTTGGTAGAGGGTCAAATGCAGCACTATTAGATATT

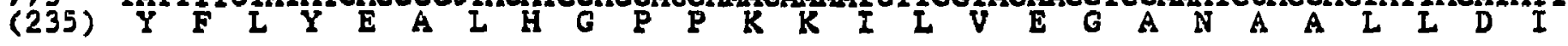

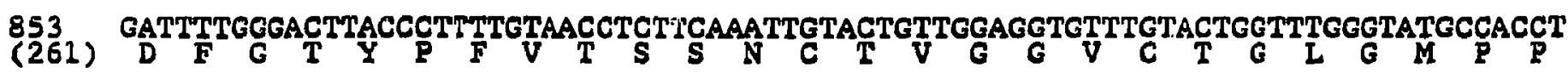

931 CAAAATGTTGGAGAAGTGTATGGAGTTGTGAAAGCTTATACAACTAGAGTTGGTATTGGTGCCTTTCCTACAGAGCAA

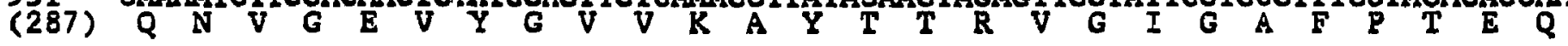

1009 GACAATGAATTGGaGAATTTTACAAACAAGGGGTGAGAGTTGGTGTAACTACTGGAAGGAGAAGAAGATGTGGC

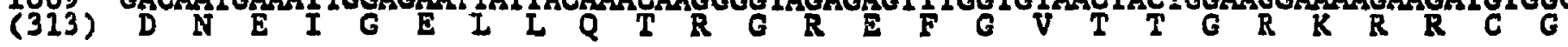

1087 TGGTTGGACCTCGTTTTCCTCAGATATGCTCATATGATCAATGGATTTACTGCGTTGGCACTTACCAAGTTCGATATT

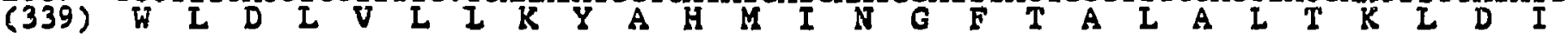
1165 TTGGACATETTTACGGAATCAGAGTGGAGTTCCTTACAAGTTAGATGGTGAAATCATACCTCATATCCCAGCAAAC (365) I $D$ M $F$ T $E$ I $K$ V G V A

1243 CAAGAAGTCTTAAATAGATTGAAGTTCAATATAGGACTCTCCCAGGATGGAGCACAGACATATCAAATGCAAGGGCG (391) Q E V L N $K$ V E V Q Y K T L $P$ G W N T D I S N A R A

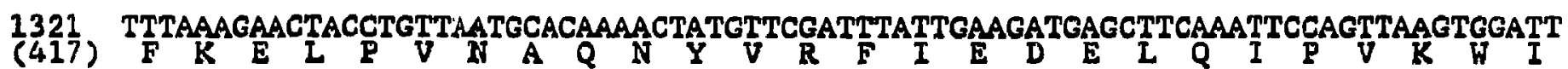
1399 GCTGTTGGTAATCCAGAGATCTATGATTCAACTCTTTTAATGATTGCCAGTAATGCAAGAAACACTCCTTGAGAGG (443) G V G K S R E S M I Q L F

1477 GAGGGGAAAAGACTTTCTAAATATTTCATTTATGACCTGCAAATTCAAGAATAAAGACACTGAAGTAAGTTGAAGCC 147TACAGTTCTTTCCAGTCTTTTCAGATGGATGCCTACTGTGGAGATTAACTTTGGCATATTCCAGTGTCAGCTTTCT 1633 TTAGCTGCAATTECCAAATCATTTETTCTCCTCCTECTCTCATGGTGCCACGTTTTTTTTTTTCAATETTTAGTAAT 1789 AGTATAATCCATGTTGTTGATATCAAAAGTAGATTACTTTATGTAGTTTCTTCATTATTGTCATTCGTETTCT CTGTCATTGTAATCTTETTETTAGAAACAATGATGAAAA ATAGGGGTTCTGTAACTTTTETATECTAT

Fig. 2. The nt sequence of the human ASCDNA and the derived amino acid sequence. The numbers shown correspond to nt while the numbers in brackets refer to amino acid residues.

was used as a probe to screen a human liver cDNA library and a single positive clone was identified. Following plaque purification, the clone was shown to contain an insert of approximately $2.0 \mathrm{~kb}$. This $2.0 \mathrm{~kb}$ fragment was subcloned into a phagemid for sequencing.

Both strands of DNA were sequenced. The single open reading frame encodes a protein of 455 amino 


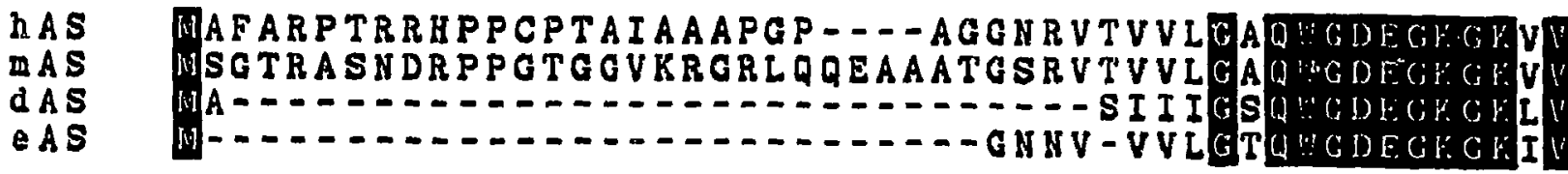

hAS

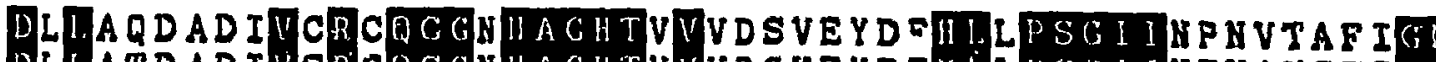
mAS dAS DLI.ATDADIVSRCQG GNHAGHTVVVDGKEYDEHILPSCI I MTKAVSFIG DILSQQFDVVARCOCGAUAGH IVVDGKKIALHLIPSGIINEKASCILCH eAs

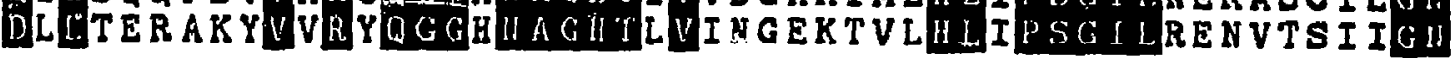

has

in AS

QAS

GVVI HL PGLFEEAEKNVQKGKGLEGWEK-- - -RLI ISDRAHIVFIEHQAA

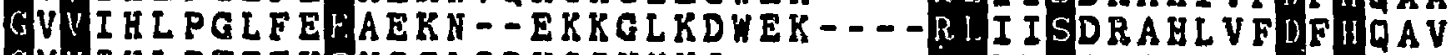
GMVI HL P TFFKFVQGLQDKGIXYKG-...-. R IFVSDRABL VFLL HOMI GVVLSPAALMKE- -..-MKELEDRGIPVRERLLLSEACPLILDYHVAL

DG I QEQQRQEQAGKNL -GTTKKGIGPVMSSKAARSGLRMCDLVSDFDCFS

hAS

mAS

dAS

QAS DGLQEVQRQAQEGKHI-C

DAMKEAELSNGTSNDSTGTTKRGIGPC DNAREKAR - - GAKAI-GTTGRG I GPAYEDKVARRGLRVGDL-FDKETFA

(112)

(114)

(191)

(187)

$(161)$

(160)

hAS

mAS

dAS

eAs

ERIKVLAN- - - QYKSIYPTLEIDIEGELQKLKGYMEKIKPMVREGWYFL ARFKNLAH-DQ L QSMFPTLEIDVEGQLKRLKGFAERIRPMVRDGVYFM KTFTRLVE-.. NKHKRFGSFEYDVEAELKRYQEFAEMLKPFVIUSVYYL EKLKEVMEYHNFQLVNYYKAEAVDYQKVLDDTMAVADILTSMVVD-VSDL

YEALHGPPKKILVEGANAALIDIDFGTYPFVTS SNCTVGGVCTGLGMPPQ YEALHGPPKKVLVEGANAALLDIDFCTY PEVTS SNCTVGGVCTGLIIPPQ NQA - FKDGKKVLIEGAQSTMLDL DFGCYPYVTSSASSVGGACT GLGISPN LDQAR QRGDEVMFEGAQGTLLDIDHGTYPYVTSSNTTAGGVATGSGLOPR NIGDVYGVVKAYTTRVGIGAFPTERINE ICDL LQNRGHEWGVTYGRKRRC KVVTQIGVVKAYTTKVGSGPFPTEQNDHVGDSLRKAGSFFGTTTGRPRRI YVDYVLGILKA Y STRVGAGPF PTELFDETGEFLCKAGNEFGATTGRRRRT GWLDLMILRYAHMVHG F TA AL TKLDILDVLSEIKVGISYKI - NGKRIPY GWLDAVVLRYTSMIIDFTRLNLTKLDVLSDFEEIKIGVDYKY - KGETIKS GULDTVAVRRAVQLHSLSOFCLT.KLDVLDGLKEVKLCVAYRMPDGREVTT

( 386$)$

$(382)$

$(355)$

(369)

eAS

hAS

mAS

aAs

eAS

IPANQEVLNKVEVQYKTLPGUNTDISNARAFKELPVN--AQNYVRFIEDE FPANQEILQKVEVEYETLPGUKADTTGARKWEDI,PPRPKATCASWR TWV FPASLETLAQCEVVYESFPGUKCDLSHVTEYDQLPIQ--AKRYIKRIEEL TPL A A DWKGVEP IYETMPGWSESTFGVKDRSGLPQA- -ALXYIKRIEEL

$(434)$

$(432)$

(403)

(417)

hAS LQIPVKWIGVGKSRESMIQ-- L - . F

IAS LQSNGSALG---SPES-_..-

DAS VGVPIVYIGVGVERKNLIERKEL- - - I

(455)

$(455)$

(427)

TGVPIDIISTDPDRTETMI - - L RDPEDA

(432)

Fig. 3. Amino acid sequence alignment of human (hAS), mouse (mAS), Dictyostelium discoidcum (dAS), E. coll (eAS). Black boxes indicate identity in all three sequences.

acids with a $M_{\mathrm{r}}$ of $49,925 \mathrm{Da}$ (Fig. 2). The predicted $M_{\mathrm{r}}$ is in agreement with $50 \mathrm{kDa}$ reported for AS from several species [2 1]. The cDNA contained a $S^{\prime}$ untranslated region of $72 \mathrm{nt}$ and a $3^{\prime}$ untranslated region of $425 \mathrm{nt}$, and it did not have a poly(A) tail. The putative initiation codon at nt 73 is not preceded by a stop codon, but it is the first $A T G$ in the sequence. The $G / C$-rich sequence surrounding the first ATG conforms to the consensus eukaryotic initiation sequence [12]. The calculated pI of the human enzyms is 7.0 .

Alignment of the human AS sequence with those from Dictyostelium discoideum [26] and $E$. coli [27] dem- 


\begin{tabular}{|c|c|}
\hline $\begin{array}{l}\mathbf{s} \\
\mathbf{S S}\end{array}$ & 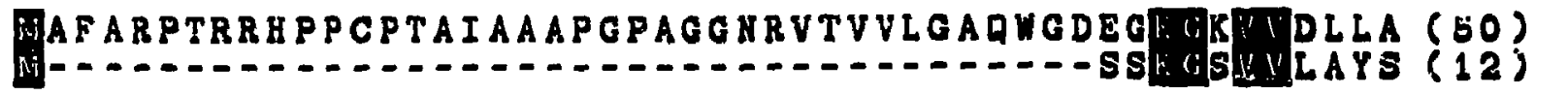 \\
\hline s & 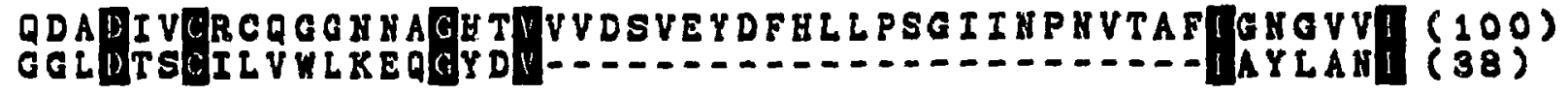 \\
\hline SS & $\begin{array}{l}\text { FDFHQAADGIUEQRR }(150) \\
\text { EELIVPA- IUSSAL }(82)\end{array}$ \\
\hline SS & $\begin{array}{l}\text { IQP Y Y SSKAAR } \\
\text { IARQVEIAOH }\end{array}$ \\
\hline 55 & $\begin{array}{l}\text { SIYPTLEIDIEGELAKL } \\
\text { KVIAYMRMPEFYKRFKGR }\end{array}$ \\
\hline 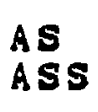 & $\begin{array}{l}\text { YEALEGPPKKIIVEGAIIAAL- } \\
\text { YEA------GIIERPXUAAP }\end{array}$ \\
\hline 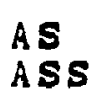 & $\begin{array}{l}\text { SWCT VGCVCTGLGM: } \\
\text { THVKDGTTHQTSLEL }\end{array}$ \\
\hline $\mathbf{S}$ & 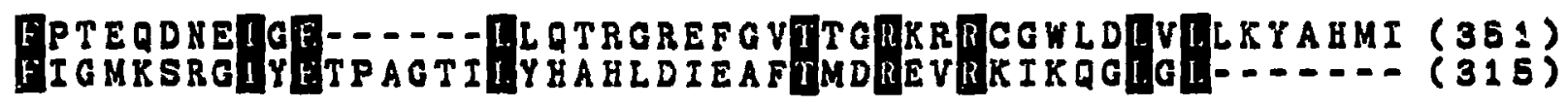 \\
\hline 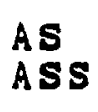 & $\begin{array}{l}\text { FIR RGVAYKLDGEITPHIP }(388) \\
\text { VEGKGUSVLKGQVYILGRE }(364)\end{array}$ \\
\hline 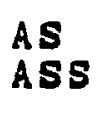 & 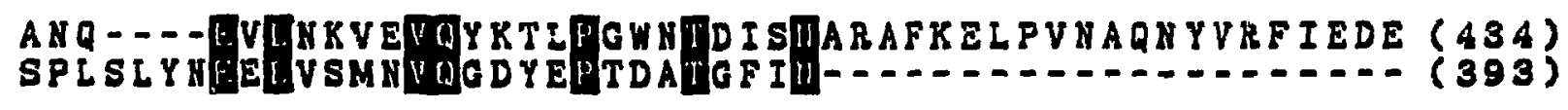 \\
\hline 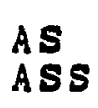 & $L Q\rceil P$ \\
\hline
\end{tabular}

Fig. 4. Alignment of human AS and ASS sequences. Identical residues are shown in black. The numbers on the riglut represent the positions of the residue at the extreme right for each enzyme.

onstrates 47 and $41 \%$ amino acid identity, respectively (F:g. 3). The mouse and human sequences have an even higher degree of identity as would be expected (Fig. 3). The degree of positional identity supports the idea that structural properties and catalytic mechanism have been retained for this enzyme throughout the course of evolution. Three motifs at residues $38-44,314-317$ and 360-363 correspond to the expected consensus elements for GTP binding, $\mathrm{GX}_{4} \mathrm{GK}$ at residues $38-44$ and DNX $_{2} \mathrm{G}$ at residues $314-317$ are thought to be involved in phosphoryl binding. A guanine recognition motif (TKKD) is present between residues 360 and 363 [26]. Also well conserved is the lysine residue at position 172 which was recently shown to be important for enzyme activity in $E$. coli by site directed mutagenesis [8].

Argininosuccinate synthetase (ASS), a urea cycle enzyme, uses aspartate as an amino donor and catalyzes reacitions similar to AS (Fig. i). Amino acid alignment of the human AS sequence demonstrated $19 \%$ identity with the human ASS [19]. The sequence identity between human AS and ASS occurs throughout the entire sequence (Fig. 4). Conserved residues are likely to have roles in maintaining structure as well as participating in substrate binding and catalysis. The fact that both enzymes utilize aspartate as a substrate suggests that some of the invariant residues within the two enzymes are likely to be required for binding.

Deficiency in ASS results in citrullinemia and a complete absence of the enzyme would be incompatible with life [11]. Several ASS mutations leading to citrullinemia have recently been characterized [11]. It was of interest to determine if any of these mutations corresponded to conserved positions found in both ASS and AS (Fig. 4). Several point mutations occur within the ASS sequence which are not conserved in AS [11]. However, an R307W substitution in patient RI corresponds to the invariant $\mathrm{Arg}^{340}$ in AS. No detailed kinetics of ASS from this patient are available [11]. We can predict, however, that the corresponding $\mathrm{R} 340 \mathrm{~W}$ mutation in AS would likely have an effect on enzyme activity similar to that noted for the R307W substitution in ASS. The AS/ASS sequence alignment also identifies additions residues 

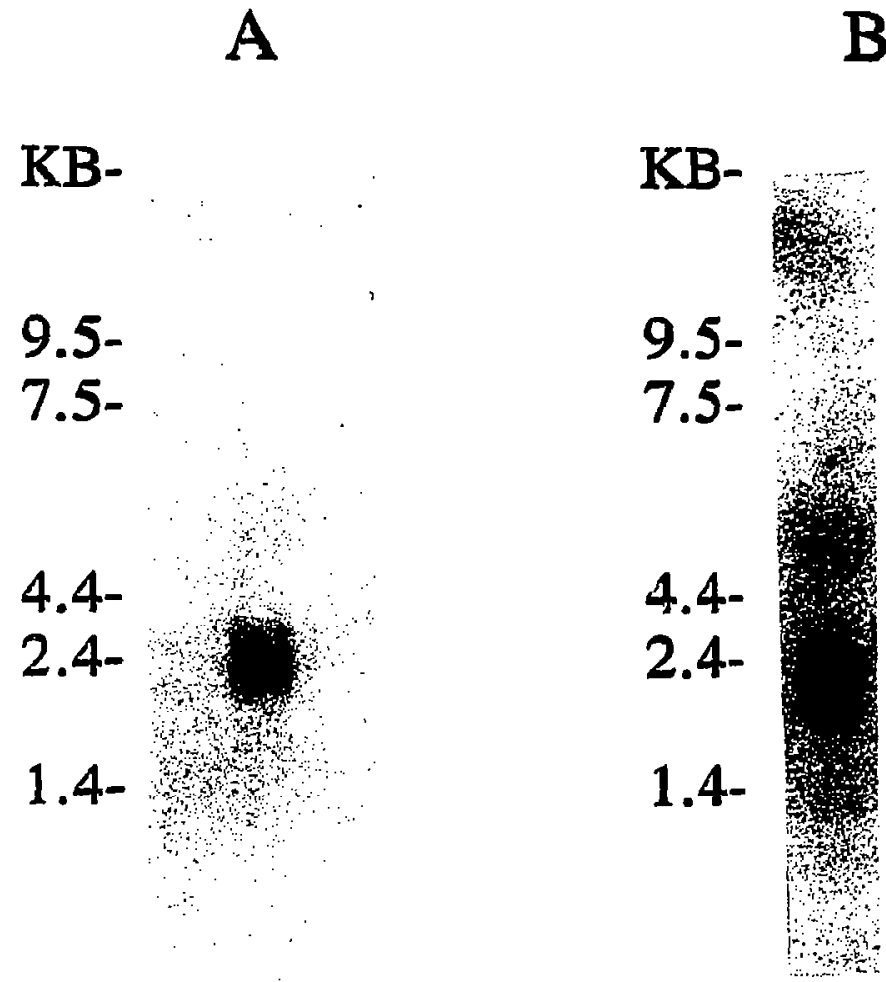

Fig. 5. RNA analysis. (A) Northern blot of human Poly(A)* RNA(5 $\mu \mathrm{g})$. Exposure was for $72 \mathrm{~h}$ at $-80^{\circ} \mathrm{C}$. An RNA ladder (BLR) was used as a size standard (kb). (B) Northern blot or HeLa RNA (20 $\mu \mathrm{g}$ total RNA).

which might be important for structure and/or catalysis and therefore suggests possible site-directed mutations to address the function of these invariant residues.

The AS cDNA hybridized to two RNAs from human liver and HeLa cells with approximately equal intensities (Fig. 5A,B). At elevated 'washing' temperatures neither RNA is selectively eluted from the filter. This suggests that the two RNAs encode a single AS isoform as opposed to encoding two distinet isoforms of AS.

\subsection{Functional complementation and conclusions}

Previous efforts to isolate AS cDNA by complementation of an $E$. coll pul' $A$ mutant with an avian expression library were not successful. Functional complementation of $E$. coli pur mutants has been used to isolate a number of enzymes in the de novo purine nt synthetic pathway from higher eukaryotes $[1,2,6,18]$. Functional complementation was attempted using the full-length human cDNA. The human cDNA clone was expressed as an in-frame, lac $Z$ fusion. Complementation of pur $A$ was not obtained. However, when the complete coding sequence was inserted into the expression vector pTRC97c, which produces the human enzyme with the correct amino terminus, complementation of two purA strains was obtained. Plasmids were isolated from $\mathrm{Pur}^{+}$transformants, then re-transformed into the same pur $A$ strains. This plasmid complemented each pur mutant with high efficiency. As expected, no $\mathrm{Pur}^{+}$transformants were noted using the pTRC-97c vector alone. This result demonstrates that the correct amino terminus of AS is necessary for activity.

The cDNA encoding human AS can be used as a tool to investigate the potential role of the enzyme in human disease. A select population of previously unclassified idiopathic, overproducing, hyperuricemic gout patients would be prime candidates for such a study. Evidence supporting a possible deficiency of AS underlying some of these cases comes from the genetic model developed with A-100 cells $[23,24]$. This cell line is a mutated mouse $T$ cell lymphoma cell which is $80 \%$ deficient in AS activity. These cells contain four-fold elevated IMP levels and secrete massive amounts of inosine into the media [23-25]. Having the human CDNA encoding AS will now make it possible to determine if any of the idiopathic gout patients' pathophysiology is associated with alterations in the AS gene.

Acknowledgements: This work was supported by the Public Health Service Grants GM 24658 (HZ) and NIDDKD 18024 (JED). We thank Dr. Randy Stone for his time donated to this project and John Williams for technical assistance. We are grateful for Dr. Frederick Rudolph for providing results from his laboratory prior to publication.

\section{REFERENCES}

[1] A.mi, J., Badylak, J., Williams, J., Chen, Z., Zalkin, H, and Dixon, J.E. (1990) J. Biol. Chem. 265, 9011-9014.

[2] Aimi, J., Qiu, H., Williams, J., Zalkin, H. and Dixon, J.E. (1990) Nucleic Acids Res. 18, 6665-6672.

[3] Amann, E., Ochs, B. and Abel, K. (1988) Gene 69, 301-315.

[4] Aviv, H. and Leder, P. (1972) Proc. Natl. Acad. Sci. USA 69. 1408-1412.

[5] Bass, M.B., Fromm, H.J. and Stayton, M.M. (1987) Arch. Biochem. Biophys. 256, 335-342.

[6] Chen, Z., Dixon, J.E. and Zalkin, H. (1990) Proc. Natl. Acad. Sci. USA 87, 3097-3101.

[7] Chirgwin, J.M., Przybyla, A.E., MacDonald, R.J. and Rutter, W.J. (1979) Biochemistry 18, 5294-5299.

[8] Dong, Q. and Fromm, H.J. (1990) J. Biol. Chem. 265, 6235-6240.

[9] Guicherit, M.O., Rudolph, F., Kellems, R. and Cooper, B. (1992) J. Biol. Chem. 266, 22582-22587.

[10] Jackson, R.C., Morris, H.P. and Weber, O. (1975) Biochem. Biophys. Res. Cummun, 66, 526-532.

[11] Kobayashi, K., Jackson, M., Tick, D., O'Brien, W. and Beaudet, A.L. (1990) J. Biol. Chem. 265, 11361-11367.

[12] Kozak, M. (1987) Nucleic Acids Res. 15, 8125-8148.

[13] Kwok, S.L.C., Ledley, F.D., Dilella, A.G., Robson, K.J.H. and Woo, S.L.C. (1985) Biochemistry 24, 556-561.

[14] Lai, L.W., Hart, I.M. and Patierson, D. (1991) Genomics 9, 322-328.

[15] Lieberman, L. (1956) J. Biol. Chem. 223, 327-339.

[16] Maniatis. T., Fritsch, E.F. and Sambrook, J. (1982) in: Molecular Cloning: A Laboratory Manual, Cold Spring Harbor Lab., NY.

[17] Muirhead, K.M. and Bishop, S.H. (1974) J. Biol. Chem. 25, $459-464$.

[18] Ni, L., Guam, K., Zaikin, H. anu Dixon, 3.E. (1991) Gene 106. 197-205.

[19] O'Bries, W.E., McInnes, R., Kalumuck, K. and Adcock, M. (1986) Proc. Natl. Acad. Sci. USA 83, 7211-7215. 
[20] Schuliz, V, and Lowenstein, J.M. (1976) J. Biol. Chan, 25I, $485-491$.

[21] Staytin, M.M., Rudolph, F.B, and Fromm, H.J. (1983) Curr. Top. Cell. Regul. 22, 103-141.

[22] Tu, A.S. and Patterson, D. (1977) Biochem. Genetics 15, 195211.

[23] Ullman, B. and Kaur, K. (1983) J. Biol. Chem. 258, 9620-9622.

[24] Ullman, B., Kaur, K, and Watts, T, (1983) Mol. Cell. Biol. 3, $1187-1196$.
[25] Ullman, B., Wormsted, M.A., Cohen, M.B. and Martin Jr, D.W. (1082) Proc. Natl. Acad. Sci. USA 79, 5127-5131.

[26] Wiesmuller, L., Wiltbrodt, J., Noegel, A.A. and Sehleicher, M. (1990) J. Biol. Chem. 266, $2380-2385$.

[27] Wolf, S.A. and Smith, J.M. (1988) J, Biol. Chem, 263, 1914719153.

[28] Zalkin, H, and Dixon, J.E. Progress in Nucleic Acid Research, Academic Press, (in press). 